\title{
Communicating on the edge of chaos: a transformation and change management perspective
}

\author{
Ronél Rensburg, Ursula Ströh
}

\author{
SUMMARY \\ 'What is chaos, that we should be mindful of it?'
}

(Josepth Ford).

Chaos will always be a mystery. Perhaps the ultimate, allencompassing mystery. To paraphrase Churchill's famous remark, it is a paradox hidden inside a puzzle shrouded by an enigma. It is visible proof of existence and uniqueness without predictability.

In the Greco-Roman tradition philosophers used logic and introspection to impose mental order on the universe. Newton, Francis Bacon and the scientists of the Renaissance chose a different path when attempting to find truth and understanding nature. In the twentieth century Einstein, Bohr and others (with quantum physics and mechanics) changed the path again, making reality even more subtle and complicated. Then, in the past twenty years, along came chaos theory. This theory, and the ways that natural processes move between order and disorder, brings us closer to understanding the planetary orbits, the shape of clouds, that phenomena never repeat themselves exactly, and even the complexity of changing and learning organisations. It is the insights and extensions of chaos theory that could carry us technologically, philosophically, socially and individually into the Age of Aquarius and possibly through our own African Renaissance.

Most managers are naturally susceptible to wishful thinking. They believe what they want to believe in spite of obvious evidence to the contrary. They try to forcefully manage and control to create balance and order in the workplace. The time has arrived for South African business leaders, managers and corporate communicators to buy into the notion that a butterfly stirring the air in Johannesburg can create a twister in New York!

This article describes chaos theory and examines how it can be utilised to provide insights into managing and communicating during times of change in chaotic organisations.

\section{INTRODUCTION}

South Africa as a country has seen significant sociopolitical changes since 1994. It is inevitable that these changes will have an influence on the South African corporate environment. Change, realignment, transformation, renewal and re-engineering are but a few of the terms currently expressed in South African organisations. There are many avenues offered by scholars and practitioners to approach change management in organisations. One of these is the chaos theory perspective - how to manage and communicate change and diversity in the current 'chaotic' organisation.

Chaos theory developed from systems theory and, much like systems theory, can be applied to a wide spectrum of disciplines (Murphy 1996:95). It is viewed as the 'scientific version of postmodernism, scientific metaphor for late-20 $0^{\text {th }}$-century cultural values of relativism, plurality, and chance' (Murphy 1996:96). Chaos theory makes a paradigm shift in postulating that forces of disorder, diversity, non-linearity, unpredictability, and instability are controlling the universe.

When an organisation is threatened by environmental changes (such as crises or competition as a result of information technology, development or increased customer demands on service and product innovation), as well as internal changes (such as transformation and structural change), the need for communication increases (Grunig 1992:344). The role of the public relations or communication manager as part of top management and strategic decisionmaking is becoming increasingly important. This is because organisations are redesigning themselves to become more open and make their structures more horizontal in order to adjust to fast-changing environments in the Communication Age (Gouillart \& Kelly 1995:290). 'Excellent' organisations use the potential of communication management to assist in transformation and relationships with the environment (Dozier et al 1995:126). Communication practitioners (managers and consultants) are also more likely to play a managerial and strategic role in an organisation in times of instability. 


\section{PUBLIC RELATIONS AND COMMUNICATION MANAGEMENT}

Grunig and Hunt (Grunig 1992:4) defined public relations as the 'management of communication between an organization and its publics.' According to Grunig, this definition equates public relations and communication management.

For the remainder of this article the term 'communication management' will be used for the reason that the term public relations is still widely misunderstood, particularly in an administrative management sense.

The concepts of organisational change and transformation refer to the process of 'reconstructing an existing organisation - removing what does not work, keeping what does, and implementing new systems, structures, or cultural values where appropriate' (Head 1997:5). Head (1997:4) explains that change efforts often fail because the changes are not communicated well, because organisations fail to align change efforts with the strategic goals of the organisation, and because they do not facilitate learning or advanced training. Well-developed organisational change should be a strategically managed process.

Studies and models of change management have either ignored the importance of strategic communication as a contribution to successful change, or communication was seen only as a tool in changing culture - one of the first stages of transformation (Gouillart \& Kelly 1995; D'Aprix 1996; Sanchez 1997). Communication management was not seen as an important contribution in guiding the complete transformation process in terms of building important relationships within and outside the organisation, thereby actually facilitating successful strategic change management.

\section{CHAOS THEORY AND STRATEGIC MANAGEMENT}

Chaos theory started out with the basic principles of systems theory and cybernetics. It grew into what is summarised by Overman (1996:487), from various definitions by other authors, as 'the study of complex, dynamic systems that reveal patterns of order out of seemingly chaotic behaviors ... the study of complex, deterministic, non-linear, dynamic systems ... so complex and dynamic, in fact, as to appear chaotic'. Chaos is 'the final state in a system's movement away from order' (Wheatley 1994:122). It can be understood as the state where a system can no longer sustain a stable pattern of behaviour because of an increasingly changing environment and subsequently leads to the system reorganising itself to adjust to these changes (Dennard 1996:498). Chaos theory attempts to understand why systems seem not to function in linear, predictable, conventional ways, but when looked at from a distance patterns and structures can be identified (Murphy 1996:96). It is a term that can be used to explain all sorts of natural and artificial phenomena such as weather patterns, stock prices, economies, traffic patterns and even biological aspects such as heart arrhythmia (Overman 1996:487). The term chaos is actually a misnomer because although it seems as if it implies total disorder and no traceable pattern, chaos is still deterministic and basically Newtonian in that it provides definite answers and methods (Overman 1996:489). Behind all the order and nonlinearity which is observed in chaos states lies an order and pattern, and new relationships and structures emerge out of what seems to be incomprehensible and out of control.

The chaos principles were derived from the new sciences of physics, mathematics, biology, and psychology and have now also been applied to the administrative sciences and the management of organisations. To understand the profound influence of the 'new science' approach to organisations, it might be of value to highlight the contrast between it and traditional views of management.

\subsection{Traditional views of management}

The traditional ontology of management science relies very heavily on the fact that systems that change cause conflict between parties involved in and influenced by the system (Dennard 1996:495). Management sees its role within this paradigm as reducing conflict, creating order, controlling chaos and simplifying all the complexities created by the environment. Within the views of Newtonian science, organisations were operated according to deterministic, predictable and stable modes (McDaniel 1997:21). Possible outcomes are predicted and alternatives for action are planned, and these are communicated throughout the organisation. If these predictions were false, management would perceive these as a mistake. Only if successful predictions were made, and activities were well planned, would organisations be effective. Risk, dissent and surprise should always be avoided and the organisation's performance is plotted out and strategically planned. Variations and disturbances would be seen as signs of poor management (Youngblood 1997:20). Great mistakes are the consequences of large causes. Conflict or crises are the results of poor planning and loose control. If employees are confused and uncomfortable, management sees this as a problem that needs to be addressed immediately (Flower 1993:50). Systems should run smoothly and according to tried and tested models and programmes. Structure and the control of having a finger on everything are the only ways to keep systems from disintegrating into total chaos and ultimately distraction (Wheatley 1994:23). Change according to this worldview is seen as 'overcoming variations to ensure the status quo' (Youngblood 1997:54).

This classical management approach, still followed in many South African organisations, 'buys' productivity and employee loyalty with benefits and compensation (Youngblood 1997:118). Income level and the employees' value are measured by the income earned. If employees do not perform as expected, negative feedback is brought in to 'take control' of the situation. This negative feedback includes activities such as 'planning, budgeting, measuring, performance reporting, analysing and summarizing' (Youngblood 
1997:54). Problem-solving strategies are the answers to problems in the organisation. Boundaries in the form of rules, authorisation levels and well-structured organisation charts create stability. Behaviour is channelled by the deeply imbedded culture of the organisation in the form of habits, procedures, norms and policies (Youngblood 1997:5).

The traditional view of management in terms of communication is that information is power and has to be controlled and 'fed to employees in little doses' (Flower 1993:51). This worldview implies that structures determine the information needed and that perceptions must be managed by feeding the 'right' information and withholding information that might lead to disorder and chaos (Youngblood 1997:62). Management 'streamlines communication' and 'interprets situations' for employees.

For many decades this approach has worked well because the pace of life was slower, managers' authority was rarely challenged, jobs were more certain and the environment was more stable (Youngblood 1997:8). But developments in information technology, information overload, better educated, well-informed employees, worldwide access to information and even family life changes (such as the roles of men and women) have caused a revolution. This turbulence in society created uncertainty and complexity, and is forcing organisations to consider new approaches and worldviews.

\subsection{New approaches to management in 'Renaissance' and postmodern South African organisations}

New approaches to management incorporate the freedom of less control and a more organic, holistic and ecological organisation (which is a living system) (McDaniel 1997:23). According to Youngblood (1997:28): 'Living systems operate in complex environments where centralized control would be a oneway ticket to extinction.' Organisations that operate like living systems are more open, flexible, creative, balanced, and respond more to the changes in the environment. These organisations are also more caring and strive towards healthy relationships with groups who could be influenced by the organisation and who could influence the organisation (Youngblood 1997:34)

Organisations can adapt, renew, maintain and move to new growth through self-organisation brought about by chaos. The contribution of the chaos theory to management lies in the appreciation of change, chaos and uncertainty and not in the distrust and need to control any disorder (Overman 1996:487). It also lies in the appreciation of the faith in the self-organising nature of chaos (Overman 1996:488; Dennard 1996:497). The interdependence of subsystems and the natural cooperating nature of these subsystems and the wholeness of reality is a further contribution of the chaos theory to the management of organisations. The self-organising abilities of systems also contribute in the sense that they provide hope for management that individual actions can make a big difference (what is termed the butterfly effect) and that there is order behind the chaos. Perceptions of control and the need to predict make a shift towards a much larger scale and order.

A very important addition is the participatory nature of the new approaches to management. Wheatley (1994:64) suggested away out of the non-objective, chaotic and complex world of the new sciences. Traditionally the interpretation of data and information was done by management, which in turn led to filtering, subjectivity, interpretation, exclusivity and over-control. She suggested that there is interdependence between different subsystems in an organisation (as the extension of the systems theory to the postmodern and complexity theories implies). This interdependence suggests that all the subsystems should take part in the processes of the system. Participation could add to richness of information, shared responsibility, more trust and transparency, and ultimately healthier relationships. Interdependence and participation in turn imply relationships, sharing in decision making, as well as in the dissemination and interpretation of information throughout the organisation.

The process and the building of relationships are pivotal and the development and maintenance of these relationships are of more importance than the outcomes or the players or objects themselves. Meaning is derived from relationships and not from the parties in isolation. Because of the interdependence of systems with the environment, relationships actually give meaning to the entities, and meaning is not situated within the entities themselves (McDaniel 1997:24).

Youngblood (1997:247) defined a relationship as the 'commitment of two or more people to supporting each other in the pursuit of a common goal'. He adds that relationships are not only relevant between people but include all living systems. The key concepts here are commitment, mutual support and common goal. Grunig and Huang (1998:23) added control mutuality - which could include mutual support, trust, and satisfaction with the relationship.

Relationship building in organisations is an indicator of successful communication management (Grunig \& Huang 1998:2). Before exploring the benefits of chaos theory and the implications of the relationship construct on communication management the most important and relevant concepts of chaos theory should be explained.

\section{CHAOTIC CONCEPTS APPLICABLE TO NEW MANAGEMENT}

\subsection{Butterfly effect and bifurcations}

Because chaotic systems are so flexible and everchanging, sudden variations can lead to points in the system where it rearranges itself around an underlying order (Murphy 1996:97). These points are called bifurcations and here the system can move in several different directions in its evolution (Wheatley 1994:96). (The word bifurcation actually means, 'place of branching or forking' (Briggs \& Peat 
1989:143).) The concept is compared to the flapping of a butterfly's wings in Hong Kong causing iteration to an unpredictable size such as a tornado in New York (Aula 1996:191), thus creating complete changes in the system's direction and extent. If these amplifications have reached a stage where they become completely unstable, described by Wheatley (1994:96) as 'crossroads between death and transformation', the bifurcation can open up futures that are totally unpredictable and exciting. This concept creates opportunities for individuals where one person can change the course of organisations by contributing in small ways or asking questions or making suggestions not previously thought of. The nonlinearity between cause and effect is again illustrated by the bifurcation effect of systems. Tiny causes can lead to big effects. In a changing environment small actions are powerful when these actions are accumulated (Dennard 1996:497).

\subsection{Strange attractors}

Disordered systems are driven by what is called a 'strange attractor'. This is a deep structure within any system that is a natural order behind the disorder and this order is taken from an attractor that traces a path in a regular pattern (Evans 1996:492). Even systems that appear to be totally out of control and unpredictable have underlying deep structures that are termed attractors (Murphy 1996:98). 'An attractor is an organizing principle, an inherent shape or state of affairs to which a phenomenon will always tend to return as it evolves, no matter how random each moment may seem' (Murphy 1996:98).

Most chaotic systems never go beyond certain boundaries - they are contained within a shape with a strange attractor holding it together (Wheatley 1994:21). Briggs and Peat (1989:73) talk about systems being constantly pulled apart and iterated towards change, transformation and disintegration although at the same time there are magnetic powers drawing these systems into order and shapes: 'eventually all orderly systems will feel the wild, seductive pull of the strange chaotic attractor' (Briggs \& Peat 1989:77).

Some authors describe organisational culture as the strange attractor that keep the organisation from oscillating into total chaos and disintegration (Murphy 1996:98). Others describe it as purpose and information. Wheatley (1994:135) described organisations that were in total chaos because of reorganisation and buyouts, yet there were employees who created meaning for themselves and carried on working productively: 'Employees were wise enough to sense that personal meaning-making was their only route out of chaos.'

If the often-quoted function of communication as 'the process of creating meaning' (Spicer 1997:188; White \& Dozier 1992:99) is taken into consideration, the importance of communication management in organisations as a possible strange attractor is rather obvious.

\subsection{Nonlinearity, scale and holism}

Systems are interdependent and all levels combine to form a 'big picture' (Youngblood 1997:47). All the actions and reactions created by changes in a system should be viewed and addressed in their entirety rather than looking at its parts. Small changes in chaotic systems can lead to amplified effects that are unpredictable. The process of growth and changes in a system is thus non-linear. Yet, if any system is viewed from a distance over time, patterns form and cycles can be observed. Looking at a single event at a given time only presents a limited view. The scale from which chaotic systems should be viewed to see order is what distinguishes chaos sciences from traditional Newtonian sciences. According to Newtonian sciences universal laws apply, whether something is viewed at its smallest part, or whether it is looked at comprehensively (Murphy 1996:97). Chaos theorists insist that significant differences can be observed in the structure and dimensions of a phenomenon, depending on the point of view taken and the instruments used to measure it. The scale of observation thus makes the difference and makes it possible to see the order in what seems totally out of control and chaotic.

\subsection{Fragmentation and interdependence}

Looking at systems from a holistic perspective provides the observer with the possibility to identify correspondences or relationships between forms that vary in scale, but compare in terms of patterns of successfully greater magnification as well as complexity (Murphy 1996:100). Each pattern takes on something from the one that preceded it and so builds a history that can be traced over time. These patterns are all interdependent and changes in one affect the other. For many physicists of the quantum world relationships are 'all there is to the reality' (Wheatley 1994:32) and they see particles as a set of relationships and interactions. The differences of entities in different relationships make for fluid and flexible systems and also make predictions and strict lines or boundaries of order impossible (Wheatley 1994:34).

Because of the interdependence of systems and the connections that form between entities, well-defined borders are broken down. The universe is energy fields coming into relationship with one another, forming something temporarily' (Flower 1993:53). Networks of information fill spaces and lead to bifurcations, and new systems and networks form (Briggs \& Peat 1989:178). Constant influences and changes in the environment, and the ever-increasing networks and relationships with outside systems eventually create 'borderless' aggregates.

Kiel (in Evans 1996:491) has adapted the principles of chaos theory to organisational management. He contends that an organisation's boundaries become blurred, and external factors and stakeholders such as citizens and the government define the parameters of dynamics and change over time. The structures of the system constantly change and this creates instability, but this instability is necessary to enable systems to 
respond to the demands of the environment. Processes should support the organisation's abilities to renew, develop and change. 'The way work is organized, the attitudes employees hold, and the technologies they use all serve to create the boundaries of performance which emerge through dialogue and process' (Evans in Kiel 1996:492).

Here lies another big paradox of chaos theory. Openness to the environment leads to greater sense of identity because of the self-organising ability of open systems. 'High levels of autonomy and identity result from staying open to information from the outside' (Wheatley 1994:92). Processes of exchange and interaction actually lead to greater freedom from influences from the environment. If an organisation builds on its core competencies, it can adjust and respond much faster to new opportunities because it is not fixed. At the same time it is sensitive to emerging markets, changes in consumer needs and threats from groups who could influence the organisation (Wheatley 1994:93; Marlow \& Wilson 1997:43).

\subsection{Diversity and creativity}

The dynamics of networks and relationships form their own source of control in learning and changing systems. Over-control inhibits the creative development of an organisation, and an unstable organisation relies more on process than on structure (Evans in Kiel 1996:492). Process implies the flattening of hierarchical structures and improving information flow and the participation of stakeholders such as employees. Loosely bounded instability is essential in order to create relationships that can respond to changes in the environment. He goes so far as to suggest that management should create instability by creating diversity and conflict.

It is at the edge of chaos that systems have the greatest potential for change, growth, development and creativity (Youngblood 1997:28; Wheatley 1994:123; Briggs \& Peat 1989:150). Creativity leads to higher orders of existence and complexity. Organisations should always leave room for creativity and new ideas. But before creativity there needs to be destruction and endings of the old (Youngblood 1997:56). This is an aspect of creativity that makes it very difficult for organisations to change and perhaps the single most destructive problem for South African organisations during transformation.

According to Youngblood (1997:59) there are three ingredients to creativity: 'information, diversity and interaction'. He contends that a creative process in an organisation leads to cross-fertilisation of a wide variety of information exchange between totally diverse entities in a non-linear and uncontrolled way. The more information, diversity and interaction, the more unstable the system will become, but it is precisely at the edge of this chaos that the most growth and creativity will occur.

Communication management is described as the process of 'overall planning, execution, and evaluation of an organization's communication' (Grunig 1992:4).
It is used to manage the relationships between an organisation and the publics on which its success or failure depends and it is in the business of negotiations, conflict management and building favourable, mutually beneficial relationships (Grunig 1992:5).

The importance and applicability of communication management in most of these characteristics of the chaos theory are very obvious and self-evident.

\section{IMPLICATIONS FOR CHANGE AND COMMUNICATION MANAGEMENT IN ORGANISATIONS}

Chaos can be described as the times in an organisation when employees are confused, feel overwhelmed and as if they cannot make sense of anything. This happens when changes and transformation occur in organisations and employees move from a state of comfort to something new. 'When people move into such deep confusion they let go of their present conceptions of how to solve a problem' (Flower 1993:51). This state of confusion and falling apart is necessary for systems to create the capacity to reorganise themselves to adapt better to the new environment. This ability to transform themselves is not possible unless systems are willing to move into the confusion and chaos (Flower 1993:51).

But what are the implications for information flow and communication management in chaotic systems that change constantly? Traditionally the immediate reaction to disorder was to clamp down on information flow and control it (Flower 1993:51).

\subsection{Free flow of information}

Flower (1993:51) suggests a radical approach to the flow of information. He posits that chaos should be created by providing an overflow of relevant and important information to such an extent that it overwhelms employees. He explains that people then get scared and frustrated and try to control the information, but feeding them with even more information finally causes them to give up and let go. Only then can people develop the ability to look at the information holistically and form knowledge and wisdom out of it all - knowledge that is adaptive and transforming.

The flow of information in a system is what keeps a system alive (Youngblood 1997:69) and it also builds strength into a system (Wheatley 1994:102). Communication managers are responsible for the creation and translation of symbols in organisations (Holtzhausen 1995:154). The more complex the system, the greater the responsibility of the manager to create shared meanings about the interpretations of symbols (Spicer 1997:188; Gayeski \& Majka 1996:24). It is also interesting that the more information is processed during times of change, conflict, and complex decision-making, the higher the quality of the decisions that are ultimately made. According to Spicer (1997:242) 'communication managers are more likely to engage in symbol creation behaviors, especially ones involving external stakeholders during times of uncertainty.' 


\subsection{Relationship management}

In the management of organisations, effectiveness is achieved when organisations attain their goals, but the goals must be appropriate to the organisation's environment. If not, strategic constituencies within that environment will keep it from achieving its goals and ultimately its mission (Grunig 1992:11). Communication management helps the organisation to achieve these goals by identifying and building healthy relationships with the strategic constituencies. The healthier these relationships are, the more likely it is that the organisation will be successful in achieving what it sets out to achieve. The quality of these relationships determines the effectiveness of the communication function within the organisation. Living systems and learning organisations should concentrate on relationships and how they work (Flower 1993:50). 'Relationships skills are no longer a luxury. They are a necessity - both in business and for our global survival' (Youngblood 1997:270).

The self-organising ability of organisations is the way organisations find order deep within the disorder of chaos (McDaniel 1997:31). This order is created because there is interaction among parties and between systems and their environments. In any organisation networks and small groups naturally evolve independently of the formal structure of the organisation. This is an example of how systems organise themselves by using communication regardless of structure and control.

New, more fluid structures will replace traditional hierarchical structures and information exchange will increase and accelerate (Marlow \& Wilson 1997:61). The network organisation as mentioned by Bush and Frohman in 1991 (Marlow \& Wilson 1997:68) is designed around communicators who 'bridge, meld, and thus create synergy amongst the organizational units'. This involves horizontal communication across departments and organisational borders in order to achieve creativity and innovation. Communication managers could fulfil the bridging functions and facilitate interaction and network building as well as contribute to management by 'helping the corporation adjust to this change by creating understanding and making knowledge more productive" (Marlow \& Wilson 1997:72).

The role of communication management is becoming increasingly relevant, if not invaluable. Its core responsibility is the maintenance of relationships and the facilitation of interaction (Grunig 1992:11; Ledingham \& Brunig 1997:27). Therefore communication becomes the basic requirement for selforganisation, and communication management becomes the strategic tool to manage interactions. Communication management entails communication with 'both external and internal publics - groups that affect the ability of an organisation to meet its goals' (Grunig 1992:4).

Kiel (in Evans 1996:492) proposes that management should create learning organisations that are flexible and fluctuating. He proposes citizen participation and stresses that although this could bring about complexity, 'empowered and involved citizens could fulfil the intention of democracy' (Evans 1996:492). They participate in the process of creating service for customers and clients. Thus they create their own reality and take ownership of it. The borders of the organisation become open and no definite lines can be distinguished. The implications for the other functions within the organisation become relevant. Strict differentiation between functions in the organisation can cause fragmentation. Subsystems should rather be more flexible with an interdisciplinary approach of working together to achieve strategic organisational goals.

Within the chaos perspective, more emphasis is placed on relationships between entities and not on the characteristics of the entities themselves (Wheatley 1994:68). 'Relationships are all there is to reality and nothing exists independent of its relationships with the environment' (McDaniel 1997:24). If communication management is all about relationship building, then the importance of this field of study to management is self-evident.

\subsection{Conflict management}

From the perspective of chaos theory, the systems approach to communication management denies the fluctuations in the environment to such an extent that nonlinearity and complexity could move the organisation into chaos and disorder. Within the chaos paradigm it is almost impossible for communication managers to be held responsible for maintaining homeostasis in an environment as volatile as the one in which organisations currently have to function.

Spicer's (1997:138) political approach comes closer to the chaos approach in the sense that it stresses that the more uncertain an environment is, the more the politics of management will come into play. Spicer suggests that because of the boundary spanning function of communication management it acts as an 'uncertainty absorbing buffer' (1997:139). During times of change uncertainty abounds and ambiguity arises because of 'our inability to understand complexity and change or our inability to forge shared understandings on how best to respond to those complexities and changes' (Spicer 1997:227).

Contrary to the Newtonian approach to organisational management, the chaos theory suggests that instead of taking responsibility for the maintenance of equilibrium with the environment, organisations could actually create chaos, dissent and ambiguity in order to stimulate growth and development. Conflict would then be only the symptom of organisations attempting to reorganise themselves (Dennard 1996:498). Managers should become 'facilitators of disorder' (Wheatley 1994:116) and should involve employees in seeking disconforming information. They should set processes in place to support the conflict that organisational ambiguity creates (Wheatley 1994:116).

Spicer (1997:266) suggests that communication managers should become more involved in strategic management decision-making as the environment becomes more complex. Relationships with the 
environment should be analysed to determine what strategies should be followed in conflict situations and a combination of collaborative and advocacy conflict management approaches should be followed. Spicer further suggests that concern over the ethical issues involved in conflict management should be the responsibility of the organisational ombudsperson. Because communication managers should know the intricacies of organisation-stakeholder relationships, they should be involved in this conflict management process.

\subsection{Diversity management}

Together with conflict management comes the new role of relationship management from the perspective of the chaos paradigm that introduces as much diversity as possible into organisations (Dennard 1996:499). Marlow and Wilson (1997:58) argue that 'innovation occurs, in part, as a result of an individual or group of individuals having the courage to highlight their relative cognitive diversity'. Diversity brings conflict and ambiguity, but it also delivers creativity, variety, strength, increased dialogue and adaptability. Employees should develop a mindset in which they can interpret, understand and appreciate diverse points of view without being taken aback by differences and diversity. Organisations will only become diverse if all groups are empowered (Marlow \& Wilson 1997:59) and again the role of ethical conscience that the communication manager could play in the organisation is of significance. There is also a direct link between excellence in communication in an organisation and the diversity of employees (Dozier et al 1995:151). Choosing channels of communication, understanding different internal and external audiences, and facilitating relationship building and two-way symmetrical communication are competencies that communication managers could bring to effective diversity management (Marlow \& Wilson 1997:59; Dozier et al 1995:151).

\subsection{Issues management and social responsibility}

As organisations transform, they carry great responsibility to the stakeholders who could be influenced by all these changes. These stakeholders should be considered in terms of decision-making and should participate in the strategic planning of the changes (Marlow \& Wilson 1997:43). As strategic managers, communicators should fulfil a boundary-spanning role, do environmental scanning, and act as a warning system in times of crises and change (Dozier et al 1995:15). Environmental scanning could alert an organisation to issues in the changing environment that could amplify and cause negative entropy in the organisation. Research is an invaluable tool for the communication manager to scan the publics affected by changes and provide information vital in building relationships, sensing conflicts and strategic decisionmaking (Dozier et al 1995:199).

As with the chaos principle of fragmentation, issues management finds the relationships between social concerns and relating issues within the organisation (Murphy 1996:103). These relationships are impossible to fully understand and identify when looking at them in a linear, quantitative, and fragmented way and patterns must be studied over time and from a distance. Linkages should be made almost with a 'sixth sense' developed by experience of the industry and through the networks and well-formed relationships that communication managers should have in place.

It seems as if the 'flow' of the different publics of the organisation could also be described and identified within the chaos paradigm (Murphy 1996:103). Just as the flapping of the butterfly's wings can gain momentum and cause a tornado, isolated dissatisfied individuals can gather force by grouping together in increasing complexity. Stakeholders that change constantly in terms of becoming more or less active, depending on the issues at stake, make it difficult for communication managers to identify points of bifurcations and the 'real' issues. Murphy suggests that they should learn from chaos theory to look further than short-term demands and complaints and search for the true strange attractors in building relationships with stakeholders (1996:103).

This is where corporate social responsibility becomes relevant as a 'concern and active two-way involvement with social, economic and political forces which influence the environment within which it exists' (Overton-De Klerk 1994). Social responsibility is a constant dialogue with the environment in order to fit the organisation to the needs of stakeholders rather than try to influence stakeholders to change according to the needs of the organisation (Murphy 1996:103). The strange attractors of a chaotic system, such as interest groups, make it very difficult to 'manage' stakeholders. They resist changes from the outside but their inherent fluctuations cause their own changes. It is thus important to build relationships with these groups through education and dialogue that might amplify to larger, unpredictable and uncontrollable effects.

All systems are independent and an organisation exists only because the environment in which it exists allows it to be lucrative. There is a symbiotic relationship between an organisation and its environment, and some of the profits generated through customers and consumers should be ploughed back into the environment (Ledingham \& Brunig 1997:27). Ethical and responsible communication managers will contribute to a better understanding between organisations and publics and also to constructive conflict management (Grunig 1993:137).

\subsection{Crisis communication management}

'Bifurcations refer to a system's condition or behaviors suddenly dividing or branching into two different or merging part behaviors' (Aula 1996:193). These bifurcations can happen if an organisation's structure becomes unstable or the environment changes so rapidly that the organisation loses control (Aula 1996:197). These bifurcation points can typically 
occur recursively and thus form bifurcation trees, which are multiple points of change and complexity and very difficult to control. This is typical of a crisis situation within an organisation.

A crisis is a bifurcation point in the 'organisation's history which irreversibly changes its culture and business' (Murphy 1996:106). These points are not random but occur because of accumulated flaws or problems within the system. But just as all crises do not necessarily lead to negative outcomes (compare the building of trust and credibility in the famous Tylenol tampering crisis), why should chaos be seen only as negative? If a system could evolve into such a large negative chaotic state, why couldn't the same momentum be used to generate positive energy and change? Communication management could turn around the negative effects caused by small events, that result in chaos (McDaniel 1997:25). A communication manager could facilitate the building of a positive value, and keep adding, very small positive differences to the initial conditions (if the current culture is seen as negative and undesirable), thereby contributing to large positive outcomes in the future state of the organisation.

Effective communication management is a critical tool in the management of a crisis situation (Marlow \& Wilson 1997:84). Organisations often experience information meltdown during a crisis, or management could decide to take total control of all information and only feed through what they consider important, necessary or 'safe'. It is at this point that open, free, and total flow of information is crucial as propagated by the chaos approach (Flower 1993:50).

\subsection{Knowledge management and learning organisations}

According to the chaos concepts of holism, systems should be understood as systems and as relationships that exist between all the entities of the system (Wheatley 1994:9). These systems are ever changing and, if viewed from a distance, display recurring patterns that have characteristics of earlier patterns. Organisations go through cycles and because of their inherent ability to change there is also an inherent need to learn (Youngblood 1997:134). The more changes occur, and the more diversity is built into the system, the more conflict becomes a regular occurrence. But this can lead to growth and development. Marlow and Wilson (1997:79) warn that employees should not only be motivated to make the correct decisions during times of change, but should also be enabled to do it and the key to empowering them is knowledge.

Marlow and Wilson (1997:79) say that an organisation's inclination to learn is directly influenced by management of information and communication. By examining the process of learning, the communication manager can contribute to effective communication through the facilitation of dialogue and the reduction of the barriers. Only by really listening to the needs of employees, encouraging team interaction, challenging existing approaches, and providing communication channels to enable this can an organisation truly learn and improve (Head 1997:197).

\subsection{From strategic planning to scenario management}

As organisations become less predictable and less controlled, what will the role of strategic planning be? It might become more important to plan strategically by looking at possible outcomes, that is scenario management. If we manage according to chaos theory, we will not be able to predict accurately (McDaniel 1997:24). The answer could thus be to look at possibilities of what could happen in future and plan for those possibilities. These plans would also have to be totally flexible and adjustable. The new slogan should be 'order without predictability' according to Cartwright, a planning expert (in Flower 1993:50).

If this is true, the importance of ongoing two-way symmetrical communication and dialogue as well as environmental scanning again become significant. The contingency approach to strategic management posits that 'organizations are most successful if they align their internal structures and processes with the demands of the environment' (Spicer 1997:61). This can only be done by maintaining positive relationships through mutual adjustment and constant dialogue and by scanning the environment for information on possible changes and crises.

Larkin and Larkin (1994:238) summarised it by saying that in the complex and changing world we live in 'the decision to restrict communication to certainty is a decision not to communication at all. Communication must be brought into alignment with the sorts of changes we are trying to communicate: uncertain, changing, and full of probabilities'.

The revolution in the technological transfer of knowledge and information has been one of the most outstanding features of the current century and will remain so as we enter the new millennium. Yet with all the hi-tech in the world, the communication gap within and between organisations has been constantly widening. In South African organisations this gap has become very pronounced since 1994, mainly because of the transformation phenomenon and the resurgence of cultural, ethnic and racial conflict. The next part of the article will attempt to address the concepts of transformation, change management and leadership, as well as the role of communication as 'strange attractor'.

\section{BEYOND MANAGEMENT: MASTERING THE ART OF CHANGE AND COMMUNICATION LEADERSHIP' IN SOUTH AFRICAN ORGANISATIONS}

The way we have designed our organisations in South Africa does not engender feelings of commitment and motivation' (Christie 1996:12). What South African organisations therefore need is a 'serious' paradigm shift in their approach to change management and leadership. 


\subsection{Transformation versus change management versus leadership}

The closely related concepts of transformation and change management are often used interchangeably, but they differ substantially. Transformation is about moving the organisation from its current state to a future state that meets the vision and objectives of the socio-political environment. Change management is a set of tools and techniques that are used to drive the transformation process.

Although both management and leadership are important in changing organisations, moving beyond management into the realm of business leadership is becoming one of the causes which have been most fervently advocated by corporate philosophers over the past few years (York Management Services 1991:5).

Leadership is different from management, but not for the reasons most people think. Leadership is not mystical or mysterious, nor does it necessarily have to do with charisma or any other exotic personality trait. Leadership is not better than management or an absolute replacement for it. Management and leadership are two distinctive and complementary systems of action. Both are necessary for success in an increasingly complex and volatile corporate environment. Management is about coping with complexity in the emergence of large organisations. Without effective management, organisations tend to become more chaotic in ways that threaten their very existence. Effective management brings a degree of order and consistency to key dimensions like the quality and profitability of products and services. Leadership, by contrast, is about coping with change.

Houghton (in Hambrick et al 1998:28) maintains that leadership is a willingness to change everything except those basic values and goals and a continual dissatisfaction with 'things as they are', as well as a drive to change things for the better.

\subsection{Corporate transformation in South Africa: a few obstacles}

South African organisations have been attracted to the notion of growth through learning and they see themselves as growing and changing institutions. Unfortunately, in many instances, the rhetoric about change and transformation has not materialised into practice. Some obstacles are the following:

- Effective transformation implementation requires the support of a concurrent drive for corporate culture change, with the individual organisation's ability to create the right infrastructure. It is not a secret that many South African organisations still maintain the status quo and battle to find an effective method of transforming themselves and managing change.

- Too many 'plans', written documents, 'bosberade', workshops and talkshops. Organisations and their members 'talk too much and do too little' about change.

- Too strong an ideological emphasis on transforma- tion and change with cosmetic results, where transformation is interpreted as halting productivity and customer service until workers' demands for internal corporate change have been met or the 'face' of the organisation has been altered completely. Change is therefore not seen as an ongoing, continuous process within organisational development and change and natural within the production and productivity cycle of business.

- People are often enablers but also disablers of change and transformation - more so than the process of technology. It is important to be aware of and embrace the human face of change. Individuals and organisations cannot achieve the outcomes they desire without building and understanding the fundamentals of their own thinking and feeling. People resist change when they do not understand the changes that are taking place; they see little or no perceived benefit of doing things differently; or they do not feel involved. Smith (1997) argues that there are seven levels of fear of change, namely paralysis (fear of doing the wrong things or doing things wrong); inefficiency (fear of wasting time and doing the right things wrong); catastrophising (fear of things getting worse); holding on (fear of letting go and wanting to be safe); self-doubt (fear of not being able to change and criticism); normalcy (fear of being different, fear of tradition and fear of the unexpected) and disbelief (fear of the point of no return). In the South African corporate environment we can also imbed into these seven levels of fear the fear of cross-racial, ethnic and intercultural interaction.

- The 'how-to' self-improvement market for organisations seems to come out with a new gimmick every month. We have seen the quality movement, team building, worker empowerment, motivational drives, etc. According to Gouillart and Kelly (1995) organisations use a lot of 'single therapies' to address their transformation problems. But no single therapy would be applicable to South African organisations.

- Organisations and in particular their communication managers have the inclination to provide information about change and transformation, but the information is often 'interpreted' and 'packaged' for employees. This implies a fear on the side of the communication manager via management of 'revealing it all'. Whatever we might say about transformation, employees will fear change and fear is driven by reversed thinking - what could go wrong as opposed to what could go right.

\subsection{Challenges for South African corporate leadership}

For many South African corporate leaders social democracy poses a threat, because there is still a protection of the old ways. Rigid structures have become defences against personal involvement. Leaders are beginning to realise that the work ethics of earlier generations no longer exist as buffers against alienated feelings. The unwillingness of South African 
managers to accept their 'Africanness' goes to the core of many organisations' poor performance. Some of the challenges for corporate South African leadership - particularly from a communication management point of view - are:

- Realigning rhetoric into reality. Organisations that made successful transformations never followed a 'quick-fix' approach. Smith (1997) empirically derived seven distinct levels of change, which he views as a strategy for organisational creativity, innovation and continuous improvement. These are effectiveness (doing the right things through problem finding and planning); efficiency (doing things right by developing basic expertise and a sense of mission); improving (doing things better by acclimatising to changes in the environment, attitudes and people); cutting (doing away with things like old habits, perceptions, stereotypes and preconceptions); copying (doing things by observing, noticing and adapting what others know and do); different (doing things no one else is doing by thinking differently, experimenting, creating new things out of old things, exploring new ground); breakout! (doing things that cannot be done by mindshifting beyond present rules, roles and operations - discovering the unknown).

- Every organisation actually has a mind of its own, and changing that mind is very often the beginning or redemption - or transformation. This is where the concepts of the chaos theory are revisited.

- The transformation of organisations is a universal issue and not only relevant to South Africa although we would like to believe this! The South African corporate environment should consider learning from transformation work done abroad, but it cannot merely transplant those ideas onto its own organisations. It will therefore be of pivotal importance to concentrate on the development of a synergistic model or framework or agenda for corporate transformation. The authors prefer to refer to it as a synergistic framework.

\subsection{A synergistic framework for transformation and communication leadership for South African organisations}

This framework should acknowledge that success for organisational learning, via development initiatives, could only be achieved when organisations appreciate the interrelationships between human resources development, management development, organisational change and development, services and/or product development, customer service and relationship development, and corporate communication management. All these must be enabled by information technology. Such a framework could help organisations to better implement learning initiatives, while providing managers, practitioners, academics and consultants with conceptual guidelines to facilitate more effective management education in the field of corporate transformation and change management.

Various suggestions for such a framework (model, agenda or checklist) can be found in the literature on transformation and change management. Considering international (Gouillart \& Kelly 1995; Smith 1997; Nadler \& Heilpern 1998: Lawrence 1998 and Biggadike 1998) and local trends (Rensburg 1998), the following synergistic framework for transformation and change management is suggested:

- An articulated management philosophy - the most effective change efforts that can be determined are those in which the core process lies in the CEO's development and ownership of an overall change philosophy - an integrated transformation and change agenda.

- A purpose - a broad statement spelling out this philosophy, vision and mission for the organisation and where it will be going. A shared vision in current South African organisations is more important than having only a plan on paper. The importance of constant communication in emphasising the vision cannot be stressed enough.

- Shared values - a description of the core values that the organisation considers most important, such as quality, innovation, service excellence and equity. Again the constant two-way interaction and facilitation of conflict creation and conflict management to work through and internalise shared values become apparent.

- Governance - an explanation of the structures and processes used to coordinate the management of the organisation.

- Organisation - broad guidelines of the architecture of the organisation - its structure, functions, processes, etc.

- Operating environment - an outline of the pattern of behaviour of employees in the organisation over time. Communication can facilitate team building, create connectivity and networking throughout the organisation.

- Operational performance - actions that will be taken to improve the effectiveness of the organisation redesign, projects and the formation of an actual transformation or change communication campaign (below).

- Talent - a plan for upgrading the organisation's talent pool to ensure organisational learning. The importance of the communication manager should be stressed here to take a leadership role and assist in this very important knowledge management function in the organisation.

A transformation or change communication campaign could include the following checklist:

- Has a corporate profile of the organisation been compiled and has the current prevailing corporate situation/ environment been assessed?

- Have the reasons for transformation been provided and the need for change been determined?

- Is leadership committed to change?

- Have appropriate support networks been established?

- Are all stakeholders committed to the process and will they continually be informed and consulted? 
- As visioning and shared values are part of the transformation process, will there be guidelines that would explain the 'full picture' of where the organisation is going to the stakeholders?

- Has an appropriate time-scale for the assessment, planning, implementation and evaluation of the process been determined?

- Have relevant corporate transformation themes been identified? Has the organisation identified the areas and topics for transformation?

- Have work units or task teams been appointed to deal with the corporate transformation themes and areas or projects of transformation?

- Is there a communication management team that would drive the transformation or change communication process?

- Has a reward system for the transformation process been installed? Did management pay attention to the 'people side' of transformation and change?

- How will customer/client loyalty be monitored during the transformation process?

\section{COMMUNICATING ON THE EDGE OF CHAOS: LESSONS FROM THE CORPORATE COMMUNICATION BATTLEFIELD}

Corporate communication managers have a pivotal role to play during the transformation and change process. Although transformation communication must be planned as part of the overall transformation and change management drive, change should never be anticipated or its direction be pre-empted.

McDaniel (1997:29) is of the opinion that it is the responsibility of management to get people together and to help them engage in dialogue so that they can improve the process of self-organisation. New leaders should constantly seek opportunities to connect groups and individuals. High-quality, long-term relationships where mutual understanding and enrichment is promoted and nurtured should be one of the key issues of strategic management (Youngblood 1997:115)

Wheatley (in Dennard 1996:499) notes that the new manager should be more concerned with the maintaining of relationships than ever before because of the self-organising nature of relationships: 'In effect, goals are secondary to those relationships that make it possible to achieve goals'. Wheatley further says that effective leadership is about the basics of guiding a vision, strong values and organisational beliefs and she stresses the leader's task to communicate these and 'keep them ever-present and clear' but still allow employees the freedom to question, discuss and think laterally (Wheatley 1994:133).

Another major contribution of chaos theory to management is the participative nature of new sciences management (Wheatley 1994:64). If employees participate in decision-making they will also take ownership of the work they are doing and they will feel that they have an emotional investment in their work. Just as reality is what is observed in quantum logic, in the same manner employees will only see a decision as 'real' if they have interacted with it, and they will only commit once they have participated.

Flower (1993:52) suggests a revolutionary idea for managers who want to motivate their employees: just don't. Because of the self-organising ability of systems, employees will make adjustments that would be required from them to prosper. It will thus not be necessary for managers to find ways to drive people but it is important to provide a suitable environment for them to develop themselves. It is interesting to note that Flower says that one of the most important factors that contribute to this 'suitable environment' is for employees to be involved in 'satisfying social relationships' (Flower 1993:52). They must be able to learn, have access to information, and be free to choose between a variety of relationships.

Flower (1993:51) and Wheatley (1994:144) mention that the chaos management approach causes many problems for managers. They are afraid to lose control and to work with so little structure. Many MBA students also reported a few years after they had completed their programme, that they 'wished they had focused more on people management skills while at school' (Wheatley 1994:144)

Communication consultants (Gayeski \& Majka 1996:5; McGoon 1994:13) suggest that communication managers' role in the chaotic organisation is changing and that it will not be enough to merely create effective technical communications such as newsletters or annual reports. They should become involved in establishing effective communication channels to facilitate dialogue, diversity of ideas, and participative decision-making. Communicators should 'learn the business and coach management to lead by example - that is the one of the most effective tools around today' (Gayeski \& Majka 1996:6). Interpersonal and management communication skills are becoming increasingly important and communication managers could assist executives in building their skills so that they can identify issues, provide contexts for information, and interpret possibilities (McGoon 1994:15; D'Aprix 1996:112).

Lawrence (1998:291) shares with us 'ten lessons from the battlefield' in efforts to transform a health maintenance organisation in the United States. Many of these can serve as lessons for managing and communicating transformation in South African organisations:

Lesson 1 Do not expect employees to embrace easily the concept of change.

Lesson 2 Sometimes it is better to experiment than to plan (back to chaos theory concepts).

Lesson 3 Pay close attention to the timing of change (refer to the bifurcation points in the chaos theory).

Lesson 4 When the need to remove employees becomes clear (for whatever reason), do not put off the inevitable.

Lesson 5 You cannot succeed without a senior team that thinks and acts as a team.

Lesson 6 Enlist the board of directors as active partners in change. 
Lesson 7 Give coherence to the transformation and change process by clearly articulating a central mission, a consistent set of themes, and-more important in terms of the chaos theory - a vision.

Lesson 8 Even though the context of change might be radical, the building process has to be methodical.

Lesson 9 Think of change as a campaign that must be waged simultaneously on a variety of fronts.

Lesson 10 This race may not have any finish line, so keep looking for reasons to stop and celebrate along the way.

To these ten lessons we can add an eleventh: Communicate! Communicate! Communicate!

\section{IN CONCLUSION}

George Bernard Shaw once observed that the reasonable man adapts himself to the world, while the unreasonable man persists in trying to adapt the world to him. Perhaps what we now need are more unreasonable men and women in leading South African organisations, with the ability to break out of the old ways of thinking and doing in order to use change to their organisations' advantage. The principles of chaos theory might provide insights of how to cope with the current 'age of unreason'.

Cyril Ramaphosa (unionist turned tycoon) maintains that 'the transformation of the South African economy is a necessary process that is going to have to take place over several years. In the process, business in this country will make numerous mistakes and, I trust, will learn numerous lessons. It will not be painless, nor will it be without its victims' (quoted in Rensburg 1998:31).

Organisational leaders will undoubtedly learn the importance of believing in individuals while valuing diversity. They will not be afraid to stimulate constructive corporate conflict and dissent (referring back to the chaos theory) and they will become healing managers - facilitating employees and organisations to grow emotionally and intellectually (Lundin \& Lundin 1993). Quality corporate relationships develop out of chaotic relationships and the healing manager facilitates this emotional pathway.

An emerging approach to organisational leadership is servant leadership. It leads from the concept of the healing manager to emphasise the importance of increased service to others - a holistic approach to work, the promotion of a sense of community, and a deeper comprehension of the spirit in the workplace (cf Greenleaf 1998).

In striving towards becoming healing managers and servant leaders in current chaotic organisations, communication managers will be more able to facilitate the 'gain' and the 'pain' of corporate transformation and change. This remains an immensely difficult task.

\section{REFERENCES}

Aula, P S 1996. Chaos and the double function of communication. In Sulis, W \& Combs, A (eds). Non-linear dynamics in human behavior, Vol 5 .

Biggadike, E R 1998. How CEOs, top teams, and boards make successful transformations. In Hambrick, D C, Nadler, D A \& Tushman, M L (eds). Navigating change: how CEOs, top teams, and boards steer transformation. Boston, Mass: Harvard Business School Press.

Briggs, J \& Peat, D F 1989. Turbulent mirror: an illustrated guide to chaos theory and the science of wholeness. New York: Harper \& Row.

Christie, P 1996. Stories from an Afman(ager). Randburg: Knowledge Resources.

D'Aprix, R 1996. Communicating for change. San Francisco: Jossey-Bass.

Davidson, J D \& Rees-Mogg, W 1997. The sovereign individual. London: Macmillan.

Dennard, L F 1996. The new paradigm in science and public administration. Public Administration Review, 56(5):495-499.

Dozier, D M, Grunig. LA \& Grunig. J E 1995. Manager's guide to excellence in public relations and communication management. New Jersey: Lawrence Erlbaum.

Evans, K G 1996. Chaos as opportunity: grounding a positive vision of management and society in the new physics. Public Administration Review, 56(5):491-494.

Flower, J 1993. The power of chaos. Healthcare Forum Journal, 36(5):48-55.

Gayeski, D M \& Maijka, J 1996. Untangling communication chaos: a communicator's conundrum for coping with change in the coming century. Communication World, 13(7) September:22-25.

Gouillart, F J \& Kelly, J N 1995. Transforming the organization. New York: McGraw-Hill.

Greenleaf, R K 1998. The power of servant leadership. San Francisco: Berrett-Koehler.

Grunig, J E (ed) 1992. Excel/ence in public relations and communication management. Hillside, New Jersey: Lawrence Erlbaum.

Grunig, J E \& Huang, Y 1998. From organization effectiveness to relationship indicators: antecedents of relationships, public relations strategies, and relationship outcomes. Chapter prepared for Ledingham, J A \& Brunig. S D Re/ationship management: a relational approach to public relations. Mahwah, NJ: Lawrence Erlbaum.

Hambrick, D C, Nadler, D A \& Tushman, M L (eds). 1998. Navigating change: how CEOs, top teams, and boards steer transformation. Boston, Massachusetts: Harvard Business School Press.

Head, C W 1997. Beyond corporate transformation: a whole systems approach to creating and sustaining high performance. Portland, Oregon: Productivity Press.

Holtzhausen, D R 1995. The role of public relations theory and research in a postmodern approach to communication management in the organization. Unpublished PhD thesis: Rand Afrikaans University, Johannesburg, South Africa.

Houghton, J R 1998. Corporate transformation and senior leadership. In Hambrick, D C, Nadler, D A \& Tushman, M L (eds). Navigating change: how CEOs, top teams, and boards steer transformation. Boston, Mass: Harvard Business School Press. 
Larkin, T J \& Larkin, S 1994. Communicating change: how to win employee support for new business directions. New York: McGraw-Hill.

Lawrence, D M 1998. Leading discontinuous change: ten lessons from the battlefront. In Hambrick, D C, Nadler, D A \& Tushman, M L (eds). Navigating change: how CEOs, top teams, and boards steer transformation. Boston, Mass: Harvard Business School Press.

Ledingham, J A \& Brunig, S D 1997. Building loyalty through community relations. PR Strategist, 3(2):27-30.

Lundin, W \& Lundin, K 1993. The healing manager: how to build quality relationships \& productive cultures at work. San Francisco: Berrett-Koehler.

Marlow, E \& Wilson, P 1997. The breakdown of hierarchy: communicating in the evolving workplace. Boston: ButterworthHeinemann.

McDaniel, R R J 1997. Strategic leadership: a view from quantum and chaos theories. Health Care Management Review 22(1):21-37.

McGoon, C 1994. What role shall we play today? Communication World, 11(7) August:12-16.

Murphy, P 1996. Chaos theory as a model for managing issues and crises. Public Relations Review, 22(2):95-113.

Nadler, D A \& Heilpern, J D 1998. The CEO in the context of discontinuous change. In Hambrick, D C, Nadler, D A \& Tushman, M L (eds). Navigating change: how CEOs, top teams, and boards steer transformation. Boston, Mass: Harvard Business School Press.

Overman, E S 1996. The new sciences of administration: chaos and quantum theory. Public Administration Review, 56(5):487491.

Overton-De Klerk, N 1994. Corporate social responsibility. In Lubbe, B \& Puth, G (eds). Public relations in South Africa: a management reader. Durban: Butterworths.

Rensburg, R S 1998. Transformation \& the South African corporate environment: a communication perspective. $P R \&$ Communications Africa, April:18-31.

Sanchez, $\mathrm{P}$ 1997. Transformation communication - the communicator's guide to organization change. New York: IABC.

Smith, R 1997. The 7 levels of change. New York: Summit.

Spicer, C 1997. Organizational public relations: a political perspective. New Jersey: Lawrence Erlbaum.

Wheatley, M J 1994. Leadership and the new science: learning about organization from an orderly universe. San Francisco: Berrett-Koehler.

Wheatley, M J 1993. A quantum vision: chaotic organization must replace the Newtonian bureaucracy. Barron's, 73(12):12.

White, J \& Dozier, D M 1992. Public relations and management decision making. In Grunig, J E (ed). Excellence in public relations and communication management. Hillside, New Jersey: Lawrence Erlbaum.

York Management Services 1991. The how to manage handbook. British Isles.

Youngblood, M D 1997. Life at the edge of chaos: creating the quantum organization. Dallas: Perceval. 